\title{
Brokers on the Ward
}

Ward Boys, Cleaners, and Gatemen in a Bangladeshi Hospital

\author{
Shahaduz Zaman \\ Department of Global Health and Infection, University of Sussex, \\ Falmer, Brighton, U K \\ Sjaak van der Geest \\ Emeritus Professor of Medical Anthropology, University of Amsterdam, \\ Amsterdam, the Netherlands
}

\begin{abstract}
This paper is based on an ethnographic study conducted in a public hospital in Bangladesh. The study shows how the social dynamics necessary to deal with the structural realities of the hospital give this cosmopolitan institution a local character. In this paper, we describe this local character by focusing on the lower-level hospital staff, such as ward boys, cleaners, and gatemen. Social inequality and exclusion are rampant in Bangladeshi public hospitals. Doctors and nurses are unwilling to communicate with patients and their relatives, while the latter are unable to approach the former for specific help or information. Our research, shows how low-level support workers fill the void between the two "factions" and act as brokers transporting information and activities between these factions. By doing so they do not only make a crucial contribution to the functioning of the ward, but also gain considerable influence in spite of their low position.
\end{abstract}

\section{Keywords}

hospital - ethnography - ward boys - support workers - brokers - social hierarchy Bangladesh 


\section{Introduction}

Early hospital ethnographies that emerged in the 1950s and 196os, which were based largely on European and North American hospitals, demonstrated the presence of a distinct social world within the hospital and documented the complex relationships between patients and staff (Caudill, 1958; Goffman, 1961; Coser, 1962). In these ethnographies, the authors considered hospital life to be an isolated (cosmopolitan) subculture. Ideas and practices that dominated hospital life were seen as coming from an international hegemony of uniform medical science. In later decades, there was a growing interest in medical anthropological studies about the diversity of medical institutions in different cultural and political settings. A number of hospital ethnographies were consequently undertaken in various Western and non-Western hospitals (Kirkpatrick, 1980; Henderson and Cohen, 1983; Sciortino, 1989; Rhodes, 199o; Finkler, 1991; Stein, 1995; Langwick, 2008). Many of these ethnographies have drawn particular attention to the relationship between the micro-level of the hospital setting and the macro-level of society. In a special issue of Social Science and Medicine, Van der Geest and Finkler (2004) contrasted the new generation of hospital ethnography with the earlier one, arguing that life in the hospital should not be regarded in such stark contrast to life outside the hospital, the so-called "real world," because it is shaped by the society in which it is situated.

Hospital ethnography subsequently developed into a strong field, and three more special issues were published. Two, in 2008, appeared in Anthropology and Medicine and the Journal of Contemporary Ethnography, and emphasised the diversity of medical settings and their relationship to the values of broader society (Long et al., 2008; Finkler et al., 2008). In a special issue of Space and Culture, Street and Coleman (2012) took a middle position, arguing that a hospital is neither an island, nor simply a microcosm of larger society, but rather a paradoxical space that is both isolated and permeable (see also Mulemi, 2010; Dapaah, 2012; Livingston, 2012; Street, 2014).

The focus of this article is on one particular aspect of wider society in Bangladesh that is strongly reflected in the hospital ward: extreme social hierarchy and the subsequent lack of communication and interaction between the mostly low-class poor patients and the medical professionals. The question that will be addressed is how the various agents in the ward manage to combine extreme social distance with physical proximity and pursue their daily activities under apparently impossible conditions. Low-ranking ward boys, cleaners, and gatemen play a central—brokering — role in answering this question. Our study shows that this brokerage not only serves the functioning of the hospi- 
tal, but also the social and financial interests of the brokers themselves. Such a phenomenon is familiar in healthcare settings in low-income societies, but is largely overlooked in the by now numerous ethnographies of hospitals and clinics that are mainly interested in the professional actors and their patients in hospital settings. Our study attempts to broaden the medical-anthropological perspective to include the "margins" of medical practices. We will return to this point in our concluding discussion.

\section{$2 \quad$ Setting}

The ethnography for this article was undertaken in a large, open orthopaedic ward in a tertiary-level government hospital in a southern district of Bangladesh that caters for the medical needs of more than three million people. Although the official capacity of the ward is 100 beds, there are usually 20 to 25 extra patients who are placed on the floor with merely a mattress or sheet on which to lie. Most of the patients are young males from a lower socio-economic background, victims of various work-related injuries, road traffic accidents, and violence. The ward is divided into male and female sections. The male section, comprising 80 beds, is the larger division of the ward. Whilst the smaller 20 bed female section of the ward remains empty for the most part, the male section is usually overflowing with patients. The reason for this skewed situation is twofold: women are less often involved in the type of accidents that lead to admission on the ward and - more generally — families are less inclined to allow women to stay (and spend the night) in a public place such as a hospital.

Other publications by the first author describe the setting in more detail. As a quick summary, it can be said that the patients, who come mainly from poor economic backgrounds, remain at the bottom of the hospital hierarchy. Doctors and other staff members are often professionally frustrated due to stressful working conditions (shortage of staff and medical facilities), bleak career prospects, and perceived lack of public recognition. Strikes related to hospital staff's dissatisfaction and demands hamper the regular flow of work in the ward. Family members are engaged in nursing and provide various kinds of support to their hospitalised relatives, while nurses have shifted from the ideal image of empathic caregivers to distant administrators (Zaman, 2004, 2005, 2009). In this hectic setting, ward boys, cleaners, and gatemen fulfill an important brokering role. 


\section{Fieldwork and Writing}

The researcher, who is both a medical doctor and an anthropologist, as well as a native Bangladeshi, acted as an observer plus participant (see also Zaman, 2008). He primarily watched the various situations and scenarios as they unfolded but also participated in some activities on a secondary basis, in the sense that he was present on the scene of the ward as a social being, watching, observing, and talking to the various people there. He also collected information through informal conversations, formal interviews, and the consultation of official records. His participation did not, however, include medical activities. He never revealed or used his physician status to the ward population. His main role was observer and his participation was in the sense that he was present in the scene and participated in conversation and in social interaction. The initial fieldwork took place over a nine-month period in 2000-2001 and resulted in a Ph.D. dissertation and book (Zaman, 2005). A supplementary observation that was conducted in 2013 revealed that conditions of class and gender discrimination and poverty had not changed. The second author was involved in the study as Ph.D. supervisor and co-authored this article. His main contribution was the theoretical framing of the ethnographic data. Direct fieldwork observations are presented by the researcher using the first person singular.

The study was conducted with the support of the Amsterdam Institute for Social Science Research (AISSR), which also provided ethical approval for the study. Permission and consent to conduct the study was also obtained from the hospital authorities and individual respondents. The Bangladeshi hospital authority provided permission to conduct the research based on the AISSR ethical approval document. Except for the head of the ward, no-one else in this study can be recognised. Individual persons who are quoted have been given fictitious names.

\section{Brokerage as a Conceptual Framework}

The term "broker" is best known today in the field of business and high finance as a person or company that buys and sells shares and bonds, and conducts transactions on behalf of a client. The most spectacular present-day type of brokerage is found on the Internet. The "Big Five" (Google, Apple, Microsoft, Amazon, and Facebook) are first and foremost platforms for communication. Their business is not making and selling products, as in the "old" economy, but facilitating communication and interaction in an extremely efficient way on a global scale. Their main capital is information and interaction, which made 
them the biggest industries in the world today. Connecting these economic giants with the small brokers on a Bangladeshi hospital ward may seem like an implausible step, but we argue that the basic principle of facilitating communication resulting in profit making is the same in both instances.

Typical "traditional" examples of brokerage that caught the attention of anthropologists can be found in the marriage market, where marriage candidates are unable or not allowed to look for a partner themselves. The marriage broker can earn a financial reward (and social prestige) for finding a suitable match for such a candidate and his/her family. Peacemakers broker between warring countries, parties, factions, or individuals who find it impossible to face one another directly.

The concept of "broker"-in its widest definition, is someone who mediates-has a long history and has had its ups and downs (Lindquist, 2015). Brokerage has proved to be a seminal concept that offers a key to understanding crucial overt as well as hidden social, economic, and political processes. The concept was particularly popular in the heyday of transactionalist anthropology (1960-1970), which emphasised the role of pursuing personal interest, individual profit making, competition, and conflict as accounting for social and political processes. This perspective implied a drastic break from a long period of anthropology that stressed harmony, stability, and communal interests.

A broker, according to Jeremy Boissevain (1974:148), is a social manipulator who "places people in touch with each other either directly or indirectly for profit." Such brokerage for profit is only possible if the parties between which the broker operates are unable or unwilling to communicate directly with each other. The inability to communicate directly can, for example, be based on social or geographical distance, different languages, physical, professional, or administrative constraints, gender, and other rules governing correct social behaviour (e.g., Whitehead, 1984), class difference, fear of pollution, lack of knowledge about the other party, political pressure, and convenience or practical reasons such as the division of work. Unwillingness to communicate may partly overlap with the above reasons given for inability; there is often only a thin line between what people cannot do and what they do not want to do. Social distance based on class, caste, ethnicity, or religion may be intensified by prejudice and emotion and present itself as unbridgeable. A broker flourishes where there are rigid societal divisions (Bailey, 1963; Adams, 1970; Blok, 1975). Transactionalism's popularity in anthropology was surprisingly limited and short-lived.

A field where the broker seems particularly relevant is healthcare. Medical anthropologists and other social scientists have emphasised the importance of mediation and "translation," particularly in the often difficult and 
inefficient communication between professionals and "lay" clients, but also in other domains of health and health services (e.g., Whitehead, 1984; Kaufert and Koolage, 1984; Schwab et al., 1988; Jezewski, 199o; Sachs and Tomson, 1994; Reeler, 1996). Communication, moreover, is a vital condition for fostering trust in treatment relationships and consequently for the quality of medical care (Rosendal Østergaard, 2015).

In this article, we argue that ward boys and their colleagues function as brokers in a-continuously shifting - community of patients, relatives, nurses, and doctors. This small community is characterised by huge social distance and inequality, which necessitates the presence of go-betweens to make adequate communication and medical care in particular possible.

\subsection{Doing Small Jobs and Mediating}

There were 14 lower level support staff in the ward: eight ward boys, one aya (the female counterpart of a ward boy), four cleaners (two male and two female), and one gateman. In addition, there were two unofficial ward boys, about whom more is written below. All of these staff were generally referred to as Class IV employees (Choturtho sreenir kormochari), which differentiates them from doctors and nursing supervisors, who are Class I and Class II/III employees. It should be pointed out that for Class IV employees there is no scope for social mobility in terms of the government job ladder. Of the 14 lowerlevel support staff, only three were female. In general, the activities and visibility of the male support staff were dominant, though this gender dimension of the lower level staff is beyond the scope of this article.

Ward boys help with the day-to-day functioning of the ward by doing small jobs that facilitate (indirect) communication between higher and lower hierarchies and are thus crucial in order for the ward to run smoothly. Most of them have little education, around five to eight years, and do not usually receive any formal training for their job in the hospital. Ward boys bring patients from the main gate or the emergency department to the ward with a trolley. They put patients in the beds that have been assigned to them by the doctor or nurse. Sometimes they do the primary washing and dressing of the patients, as ordered by the doctors or before the doctor comes. They also help the doctors during dressing and plastering. They help nurses by holding the patients when they administer injections. They take the patients to different departments, such as X-ray or pathology, to which they have been referred. Ward boys take patients to the operating theatre and help position them on the operating table. They shave the intimate parts of the patient before an operation. They serve as couriers, carrying patients' files and doctors' messages to different departments, bringing medicines from the hospital pharmacy, and carrying 
instruments to the autoclave room for disinfection. As patients receive no information from doctors or nurses about their diagnosis, prognosis, operation date, discharge date, etc., it is ward boys who extract this information (mainly from nurses) and convey it to patients. The ward boys have some control over bed allocation, providing bed pans and wheelchairs to patients, and they prioritise and give advantages to patients who provide them with bakshees. Whether a relative will be allowed to stay in the corridor during the doctor's round or chased out of the gate will depend on whether they make the ward boy or gateman happy; the corridor is a space where the latter have control.

Ward boys sometimes carry out the duty of gatekeeping as well. Within the hospital, there is a post called MLss (Member of Lower Subordinate Staff Service), a name given by the British to the lowest rank in an office hierarchy; this person usually works as a gateman. But as it is not possible for one person to control the two main entrances to the ward, the ward boys also perform this task. Finally, they provide various informal services to doctors, like serving tea, fetching a pack of cigarettes, and so on.

Ayas do the same activities as ward boys, but in the female section. The ward in which the research was conducted had only one aya, who was not always present. The researcher did not have chance to talk to her much, so we have little information on the specific aspects of these female workers. In any case, gender differences were not a focus of this research.

As they bring patients to the ward, ward boys are the first human contact that patients and their relatives have before they enter. They are thus the initial socialising agents for patients. Doctors and nurses pass on hardly any information to patients, so it is from ward boys that patients and relatives learn how the hospital and the ward function, and even the nature of their health condition. Moreover, poor patients feel socially closer to the lower level hospital staff than to the doctors or nurses. As the ward boys have access at least to the nurses, they sometimes manage to get some medical information about patients from them. Patients thus get to know their operation date in advance and are informed about any changes in their treatment plan through the ward boys. However, on many occasions, ward boys also give vague or even false answers to patients in order to maintain their status among them and secure their brokerage position. One day, I saw a ward boy holding up an X-ray plate, explaining to the patient: "Can't you see your bone has broken into four pieces? Each piece will take one month to heal. That is how it works."

Another lower level role performed in the ward is that of cleaner. Gonesh was in his mid-4os and had been working in the hospital as a cleaner for more than 20 years. He came from a lower-caste Hindu family. His father was also a cleaner in the government municipality office. Cleaners are responsible for 
sweeping and mopping the floors, and cleaning the toilets and basins. They usually do this twice a day, every morning and evening. The cleaners sluice and clean the operating theatre after surgery and rinse bloodstained linen, surgeons' vests and caps. They also carry all the linen from the ward to the central laundry and bring clean linen back. In addition to these duties, the cleaners also do many of the activities of the ward boys mentioned above.

All of these low-level staff are also involved in maintaining discipline on the ward. They control the entrance of visitors and relatives into the ward, and are responsible for keeping the ward free of visitors outside of visiting hours.

In contrast to the transactionalist perspective, which views the broker mostly as an initiator of change, our ethnography in a Bangladeshi hospital setting shows that these low-ranking brokers are instrumental in keeping the existing hierarchical and gender divisions intact in a situation where one would expect such divisions to diminish, given the type of work that must be done. In the hospital, doctors and nurses come into close physical contact with patients, people with whom they would hardly interact in ordinary life. Ward boys and others are employed to soften this dilemma and keep the ward running. Hadley and Roques (2007:1161), who studied the changing roles of nurses in Bangladesh, compiled the following list of nurses' activities that are, in fact, carried out by "support workers" such as ward boys, in addition to their tasks of cleaning and gatekeeping:

Support workers were involved in a large number of activities that were described in the nurse-training curriculum. These included insertion and care of urinary catheters in male and female patients, replacing intravenous fluids bottles, changing wound dressings, checking for signs of bleeding in patients post-surgery, feeding through naso-gastric tubes, distributing patients' meals, providing bedpans, administering enemas, shaving pre-operative patients and assisting doctors with procedures, such as dressings.

\subsection{Bakshees}

For any service provided by these lower-level staff, patients are supposed to pay bakshees. The practice of paying bakshees, which can be translated as tips or bribes, is an open secret on the ward. Ward boys, cleaners, and gatemen augment their meagre income by demanding bakshees from patients. The money transaction does not take place openly; it is usually done outside the ward in the busy corridor and lobby or beside the bed during the crowded visiting hours, so that the transaction is not overtly visible. Ward boys are paid bakshees for bringing patients to the ward, taking them to radiology and other departments 
when they are referred there, and escorting them outside after discharge. Rates for this range from 20 to 50 taka ( 20 to 50 us Dollar cents). We estimate that bakshees comprise at least half of ward boys' monthly salaries.

Doctors and nurses do not give bakshees to ward boys. As explained before, the ward boys work in a robust hierarchical relationship with doctors and nurses, and their functioning depends largely on the favour of the latter. The ward boys are in competition with each other to please the doctors in particular. Doctors are "patrons," and thus they do not need to impress a ward boy for support.

Patients also need to pay small sums to the gateman so that visitors are able to stay closer to their relatives, at least on the veranda parallel to the ward, if not inside the ward itself, during the ward round. Moreover, passes are issued for one visitor per patient, but usually several family members want to meet the patient and the gateman allows the extra visitors, provided they offer him a small payment. Some also pay the gateman so that he will permit them to stay in the ward a little longer than the official visiting hours. His charges vary, but range from 10 to 30 taka (10 to 30 us Dollar cents).

Paying the cleaner is a must if one wants to receive any services from him. The patients often need assistance when they use the toilet. In most cases, relatives assist but relatives are not allowed to stay the whole day, and moreover, some patients do not have any relatives to help them, so they need assistance from the cleaner. Cleaners are relatively cheaper, and cost only 5 to 10 taka (5 to 10 us Dollar cents), depending on the job. Helping with urination is 5 taka, while assisting with defecation is 10 taka.

The receipt of bakshees illustrates the entrepreneurial and profit-oriented character of brokerage mentioned earlier. These secret-but generally known - transactions augment the very low salary that ward boys and their low-ranked colleagues earn. This financial profit goes hand in hand with gaining influence and power. The practice of hidden profit-making is elaborated upon in the later section on "clandestine business."

\subsection{Disciplining Patients and Relatives}

Doctors and nurses delegate the responsibility of maintaining discipline on the ward to the ward boys and gatemen. They remove the visitors from the ward during the ward round and after visiting hours, which is no easy task. They drive the patients' relatives away with verbal and physical violence, including scolding, slapping, and beating. This sort of behaviour is approved of by the doctors and nurses, who allow the ward boys and gatemen to use any means necessary to get the relatives out of the ward. I heard a doctor say to a ward boy: "Hit that chap with your stick and throw him out of here." 
Emboldened by the authorisation of the doctors, the ward boys and gatemen are particularly cruel to relatives, and patients expressed their distress over their malicious behaviour. One patient described to me how one ward boy had pushed his old mother so hard that she fell down on the floor. Another complained that the ward boys always addressed the patients as tui (the less formal address) and not as apni (the more formal one), irrespective of their social status. In Bengali, people usually address a stranger as apni, while tui is used by seniors to address juniors, by higher social-class persons to address someone from a lower class, or it is used inappropriately to humiliate someone. This was considered unacceptable by all patients, irrespective of their social class. A patient who was a day labourer said: "This ward boy is just a labourer like me. But he behaves like a big borolok [boss]. He is a poor man and he should have sympathy for the poor." A relatively well-off trader said: "These worthless cleaners and ward boys would never have dared to enter my house or talk to me, but now I am such an unfortunate that they are even scolding me."

The complaints of patients about the cruel and "unacceptable" behaviour of ward boys show the delicate position of brokers, who have to balance between the parties they communicate with. The fact that they act under the authorisation of the doctors makes them somewhat invulnerable vis-à-vis the patients and their relatives. The roughness of their behaviour is enacted "on behalf" of the doctors and nurses, who thereby keep their hands "clean." This balancing act of the ward boys creates the informal power they possess in the ward and makes them indispensable.

\subsection{Two Different Ward Boys}

There were exceptions, however. I (the researcher) was surprised to observe that there were two ward boys who rarely scolded the patients and maintained quite good behaviour. Later, I discovered that they were not official ward boys, but were informally allowed to work on the ward due to a serious shortage of support staff; the doctors permitted them to help the other ward boys, who were happy to have helping hands. They did not receive any salary from the government but lived off the bakshees of patients. The more they pleased the patients, the more they earned. They had to keep the ward boys, nurses, and doctors happy, too, since if they were not pleased they could forbid them to work. Thus, the existence of the unofficial ward boys depended on the mercy of the other staff members and the patients. Their precarious position made them behave nicely with the patients; in fact, they were the only staff members who did not humiliate the patients.

Interestingly, both of these unofficial ward boys had once been attending relatives of long-term patients on the ward. Their experience of caring for their 
relatives meant that they were familiar with the ward and this had helped them to get the job. One of them, Akbar Hossain, told his story:

One of my uncles had a road accident and was admitted in the hospital for many days. His two sons were busy, so they asked me to stay with my uncle. I didn't have a job; therefore, I agreed. I do not have good school education, and could not find ways to earn money. I was quite helpless at that time. I took care of my uncle in the hospital. My cousins used to come; they also gave me money. I could have food in the hospital. My uncle stayed in the hospital for three months. I spent the whole day in the hospital ... Different activities of the ward became familiar to me. I almost became part of the ward and was known to everyone. In the later part of my uncle's stay, when he became a little better, I also started helping other patients; as some of them did not have any attendants, I helped them and they gave me little tips for that. Moreover, the hospital ward boys were busy with other work, while I was always present in the ward, so I could attend any patient who needed help. When my uncle was discharged, I thought I should stay in the hospital and continue doing this job because I had no job outside. Here, I know the place and also can earn some money. I asked the hospital ward boys; they did not object. They talked with the doctors and the doctors permitted me to work. It's already eight years since I started working here.

The unofficial ward boys were, however, unhappy about their vulnerable position; they were the lowest of the low in the hierarchy. The other unofficial ward boy, Kutub, said:

Sir, we are the orphans of the hospital. There is no-one to look after us. If we make some slight mistake all the other staff members shout at us. Ward boys, nurses, and doctors, everyone threatens to dismiss us from the job. As we are not official employees, we are not members of the association of the Class IV employees. There is no-one to fight for us.

Although the doctors allowed the unofficial ward boys to work in the ward, it would have been difficult for them to function without the cooperation of the official wards boys. In order to receive this support, the unofficial ward boys gave part of their daily earnings to the official ward boys. As a result, they earned only a very small amount of money. They also had no fixed timetable for work. The longer they stayed in the ward, the more they earned. Sometimes, when 
they had not earned enough, they stayed in the ward 24 hours a day, and after spending a whole week in the hospital they would go home to their family.

The low position and salary of the official ward boys could give them the appearance of informal workers in the formal structure of the hospital. Yet, the two unofficial ward boys were truly informal and lived from bakshees alone. They were "beginners" in brokering and hoped to obtain a better brokerage position once they had made themselves indispensable. For the time being, however, they had to content themselves with bakshees, which, though hard, was possible.

\subsection{Clandestine Business}

Many of the Class IV employees have a hidden network involving pharmacies and commercial drug sellers around the hospital. The drug shops buy the medicines and other materials that the Class IV employees have stolen from the hospital, which they then sell to the patients for more than they paid the ward boys. The fact that the lower-level staff steal hospital supplies, such as medicines and food, is also a public secret, like their practice of taking bakshees. The ward boy responsible for bringing medicines from the hospital's central drug store to the ward pilfers some medicines on the way. Other ward boys also sometimes steal medicines from what is purchased by relatives from an outside shop, which must be handed over to the ward boy prior to surgery. In addition, ward boys take medicines and other surgical items that remain unused after an operation or when a patient is discharged. Sometimes they are caught but most of time not. One day during the fieldwork, a stack of medicines and surgical materials was found in an abandoned locker in the toilet. Nobody admitted responsibility. It was, however, clear to everyone that these items had been stolen by a ward boy and were being kept there for future removal.

Assistance is needed to help patients find their way and survive in an unknown world. The ward boys are the only guides who have time and are accessible in this new situation - for a modest sum of money. In addition, ward boys can further exploit their position by expanding their business to illegal transactions with stolen goods, in particular medicines. These transactions show the articulation of formal and informal activities that have been signalled by various students of healthcare, particularly in low-income societies. Studies of the articulation of formal and informal/illegal practices in healthcare settings include, among others: Van der Geest $(1982,1988)$, Jitta and Van der Heijden (1993), McPake et al. (1999), Ferrinho et al. (2004), Martin (2009), and Praspaliauskiene (2016).

The concept of "articulation" (connecting) is in our view closely linked to brokerage. The analysis of the-often obscured—connection between formal 
and informal reveals how the formal economy cannot function as it does without the informal economy. Corruption is generally regarded as detrimental for the quality of healthcare but it is sometimes seen as the lesser of two evils when formal services fail. In the case of the ward boys' pilfering of medicines, however, we argue that it seems generally detrimental, except of course to their own pockets.

Ward Boys Speaking

Ali, the senior ward boy, sometimes also worked as a gateman and usually behaved very badly towards patients and their relatives, shouting at and slapping them whenever he got the chance. Patients disliked him more than any of the lower-level staff. One patient told me: "I wish I could slap him one day." In the last phase of my fieldwork, I asked Rahim Ali what he thought of his job. In reply, he made a funny gesture: he bowed and showed me his bald head. Then he told me:

Ali: Look at my head. There is not a single hair left. I lost all my hair because of this job. This is a terribly bad job. One cannot be a normal man anymore if one stands at this gate and fights all day with this crowd. If you give me another job, I will quit this one immediately.

Researcher: People say that you behave very rudely towards them.

Ali:You have been here for some months; you have seen how unruly these people are. They will never get out of the ward unless you force them. In this country, nothing works with sweet words (misti kothay kaj hobe na). Unless we shout, they will never listen. If they are not out in time, the professor and other doctors get very angry with me. If I am not rude to the patients and their relatives, the doctors will be rude to me. But frankly, doctors are ruder to the patients than we. They treat patients badly and leave the hospital with their cars. But I do not have a car to hide in. So if I become too rude they will catch me outside and beat me.

Actually, it is the doctors who force us to behave rudely. They tell us to use sticks on the relatives. I know it is cruel. Moreover, doctors need the relatives. One day a man was waiting in the veranda outside the ward close to the window. His mother was severely injured in a car accident. She was crying, so I allowed her son to stand outside the ward so that she could see him from her bed. But when the professor saw her son, he 
was very angry and asked me to tell him to get out immediately. I led him out of the ward. But then, during the round, the professor needed to know something about the woman and looked for her son. [When he didn't find him] he asked me to find him. I looked for him but he was already gone. Then the doctors had a problem. What can I do? I did what they wanted me to do. I have to save my job.

Gonesh, the cleaner, spoke about his own frustrations:

Sir, we do a choto [small] job, but when there is no-one to do a job, we are there. We are nurses, ward boys, gatemen, and cleaners all in one. We do everyone's job, but nobody does our job. Cleaning the dirt is solely our responsibility. Doctors are angry when they see the ward dirty. You have seen how it becomes a bazaar during the visiting hours. Hundreds of visitors come to the ward. They throw everything on the floor. We are the only ones on duty in the morning and in the evening. It is a huge task to sweep this big ward alone. We also cannot keep the toilet clean. Sometimes I find it difficult to enter into the toilet. I wash it once in the morning. But how is it possible to keep it clean? So many people use it throughout the day. Sometimes there is no water. For the last 15 days there has been no bleaching powder, soap, or Fenyle [an antiseptic solution]. I told the nurses and doctors, but I am still waiting for the materials. How can I do my job properly?

When I asked him about bakshees, he said: "I get about 2,0oo taka [about 30 USD] a month [the salary for cleaners has recently been increased]. How can a family survive on that amount? I cannot feed my family with that money, not even for half a month. I need some extra income. I ask it from the patients. I give them service and they pay me when they are pleased."

When Ali, in the above interview, told the story of the professor who had forced him to remove a relative, and later realised that he needed the relative, he concluded with a comment that succinctly summarised the ward boys' raison d'être: "The doctors had a problem." Without their mediation between patients/relatives and medical staff, doctors would be in trouble. But his story also points to another aspect of their work: Being a broker does not only bring rewards and power, but also implies suffering the anger and "blows" of both parties. Mediators are often beaten, both proverbially and in reality. 
Ward boys, cleaners, and gatemen are the lowest staff in the hospital hierarchy, but they occupy a pivotal and powerful position in the hospital in Bangladesh. They have made themselves indispensable for doctors, nurses, and patients by bridging the gap between two "factions" that need one another but are unable or unwilling to communicate. As brokers, the ward boys and their colleagues carry out activities that doctors and nurses refuse or cannot do. Hadley et al. (2007:1166) remarked that nurses in Bangladeshi government hospitals minimise the stigma associated with their profession by distancing themselves from patients, "using nurse surrogates in the form of patients' relatives and hospital support workers to carry out their work." Conversely, ward boys also help patients and relatives to "communicate" with nurses and doctors, whom they cannot or dare not approach directly.

Ward boys do all sorts of manual labour that is necessary for the everyday functioning of the ward. Because of the reasons just mentioned and the shortage of staff at the hospital, they assist the nurses and doctors in dressing, plastering, and bandaging wounds. Sometimes they perform the more minor medical tasks by themselves. In addition, they are the main agents who maintain discipline on the ward, controlling the admission of patients' relatives and visitors. As mentioned, the patients and visitors mainly come from lower socioeconomic backgrounds and find it difficult to comprehend the rules and routines of the hospital. Moreover, many are confused and nervous due to dealing with their own or their relative's serious health condition. As a result, conditions on the ward are often chaotic. The doctors, however, want there to be discipline in order to carry out their job, and they delegate this responsibility to the lower-level staff. Empowered by the doctors' approval of the use of coercion, the lower-level staff maintain discipline by use of force, which is sometimes quite cruel. They physically and verbally abuse the patients and visitors in front of the doctors. The doctors have this "dirty work" carried out by the lower-level staff, thus saving themselves from crossing the class boundary.

The extraction of labour, services, and respect from persons of lower rank by persons of higher rank is common in Bangladesh, as it is in many other South Asian countries. A person of higher rank expects services and respect in exchange for patronage. A number of observers of Bangladeshi culture have noted the remarkable preoccupation of Bangladeshis with social status and rank:

Every individual [in Bangladesh] knows and is quick to estimate who is above and who is below him. Indication of rank is displayed in casual 
conversations and official inquiries, whereby persons are specified by references to skin colour, size of salary, academic degree and birth order within the family.

KOTALOVA, 1996:148

Social inequality in Bangladeshi society is rooted in three ideological values, namely individualism induced by Westernisation, the hierarchy that characterises peasant society, and behaviour shaped by the religion of Islam.

MANNAN, 2015:24-28

Hierarchy informs much Bengali behaviour. Rank depends on wealth, education, lineage, clan, employment, and differences in age. When people meet every day, they try to assess and establish each other's relative rank.

MANNAN, 2O15:24; see also MALONEY 1986:40-66

Life within the hospital ward clearly demonstrates this obsession with hierarchy. The interactions within the ward show a constant concern on the part of staff to define the boundaries and maintain the institutionalised inequality between themselves and the patients/attendants, as well as between the different grades of staff. The ward boys, however, have access to the nurses and manage to bring patients or relatives medical information from them. The language, gestures, and overall demeanour of the staff members indicate who is "big" and who is "small" in the ward; the status of patients and their relatives is below that of the lowest-level hospital staff, even if the patients are middle class.

Despite their cruelty, ward boys and cleaners are also indispensable to patients. Patients are socially closer to the lower-level staff than to the doctors or nurses. Because of the clear hierarchy and the dominance of the medical personnel, patients are hardly ever able to communicate with the doctors or nurses. As a result, the lower-level staff may be the only hospital personnel with whom they manage to communicate. They are the socialising agents for the patients and instruct them on how the hospital works.

We have seen how the Class IV employees exploit this broker position for economic gain. For any service rendered by them, patients have to pay bakshees. They are the lowest paid employees of the hospital, so they need this extra income. Andaleeb (2000:96), who studied the service quality of private and public hospitals in Bangladesh, wrote: "In many service sectors, even the most basic services are often difficult to obtain without bakshees. At times 
patients' fate may be determined by their ability to provide bakshees". Hadley et al. (2007:1173) illuminate the confusion felt by patients and their carers regarding payment to ward boys with the following quote from a patient:

We paid because he [the hospital support worker] demanded it. He told us that everybody needs to pay for that service. Since we were new in the hospital, we didn't know anything about the system. We could not refuse what he was asking because he seemed to be powerful in the hospital.

In contrast, in private hospitals the practice of bakshees is limited. As patients must pay a lot to be in these hospitals, they can demand services and do not need to facilitate them through the additional payment of bakshees. When clients of a private hospital do pay bakshees to lower-level staff, it is therefore done on a more voluntary basis and with the cultural spirit/norm of rich people sharing their wealth with the poor.

It was observed that there are also other ways for ward boys to augment their paltry income. They maintain obscure business links with the surrounding medical shops, where they sell the drugs and materials that they pilfer from the hospital store or patients. They also steal other property from the hospital and patients. The ward boys in particular have access to medicines and equipment as they carry materials from one department to another or from patients to nurses or doctors. Being at home in two different worlds, the formal and informal health sector, they are also able to move the medicines from formal to informal facilities. Roy (2009), who carried out research in Indian cities, argues that informality is not a failure of planning or an absence of the state, but rather a system of deregulation, which can be thought of as a mode of regulation. In other words, deregulation is calculated informality. The functioning of ward boys in Bangladeshi hospitals illustrates this point well.

What are the ethnographic and theoretical implications of our arguments for the wider field of medical anthropology and hospital ethnography in particular? The role of low-ranking workers in hospitals is generally overlooked in ethnography. In hospitals and clinics in high-income countries, their work is strictly separated from professional medical practices and they carry out their activities almost invisibly. There is no need for them as brokers of communication as-generally-direct communication between professionals (nurses in particular) and patients takes place and is considered essential for efficient medical care. This is not to say that their work has no relevance for medical staff, but it does perhaps explain why they are all but absent in ethnographies of affluent medical institutions. Their role in modern medical facilities does, however, deserve more attention, certainly from the perspectives of hygiene, 
gender, ethnicity, and hierarchy. A notable exception in this regard is Rapport's (2009) study on the orderlies of a Scottish hospital. Rapport's ethnography explored the portering community of the hospital and revealed how they resist, subvert, transcend the hospital regimen and, individually and collectively, exercise power to construct their own "wellness" at work.

The role of cleaners, ward boys, and gatemen in medical facilities in lowincome societies is more prominent and visible, yet still relatively overlooked in ethnographic studies. In several studies, ward boys, support workers, orderlies, cleaners, sweepers, or whatever they are called, appear briefly in the descriptions of hospital activities (e.g., Brown, 2012; Dapaah, 2012; Street, 2012; Livingston, 2012; Tantchou, 2014), though without getting the attention they may deserve. A few studies, however, have paid attention to them and have not only observed them, but have also let them speak about their position and their work. Christine Böhmig (2010), who focused on nurses in a Ghanaian university hospital, recorded the many activities of cleaners and other low-ranked workers. The following quote from a female cleaner summarises their daily programme:

I start my work at 6:30, latest by 7:00, and we close around 4:00. We work every day and are one day off a week. We had no training but just do our work. We are four female cleaners for the ward. Our task is to clean the ward, the tables, lockers and windows. We do not do the sweeping, this is done by the men. And we also distribute the food, breakfast around 7:00 and lunch around 14:00. In the morning, the males get the breakfast from the main kitchen and it is our duty to distribute it. After that we clean the used bowls in our kitchen here before we send it back to the main kitchen. The same goes with lunch. Today, I work here in the toilet. The toilets are cleaned twice a day by the men, we just do the bedpans.

p. 197

Böhmig emphasises their low position in the hierarchy but shows at the same time that they regard their contribution to the work on the ward (hygiene) as important and indispensable. Furthermore, in spite of the hierarchy, most have good relationships with the nurses, though the doctors are beyond their social horizon.

Benson Mulemi (2010), who wrote an ethnography of a cancer ward in a large Kenyan hospital, made a few remarkable observations about the role of its cleaning personnel. Patients referred to them as "small people," but did so with affection. Their low position brought them closer to the patients, who 
found doctors and nurses more difficult to approach. The following remark by a patient illustrates this:

Those who are close to us are different from those who are up there. You feel a kind of loving care you would like to receive when they are close [...] They try to find out how we are doing. It is so irritating when somebody runs away from you. I get discouraged and feel rejected. We relate more to these "small people" [...] Doctors and some sisters are up there [...] The people who bring food, medicine and the cleaners are more loving $[. .$. they talk to you well.

p. 94

Diana Gibson's (1999:234) hospital study in Cape Town, South Africa mentions yet another activity of cleaning personnel: Interpreting for a doctor who does not speak the language of a patient.

Most extensive about the work of "support workers" is Mary Hadley, whom we quoted above. It is probably no coincidence that she also studied hospital culture in Bangladesh. The structural and firmly established involvement of untrained lower level personnel in medical practice may well be a typical Bangladeshi phenomenon. Hadley and her co-authors also point to the mediating roles of these support workers, although the term "broker" never falls. "A new order involving informal systems has evolved," they write, "whereby support workers use their willingness to carry out dirty work [...] to manipulate the system to their advantage, positioning themselves in places of power" (p. 1176). Nurses avoid tasks perceived to be distasteful and in conflict with social and gender roles by using hospital support workers (and patient carers) to perform these undesirable tasks (p. 1171). Böhmig (2010) and Mulemi (2010) also hint at brokerage when they point to mediating practices. A prominent element that repeatedly returns in their discussions is that the low social position of these workers seems to play a decisive role in their ability to broker; thus they can be seen as both "hospital trash" (Messing, 1998) on the one hand, and indispensable and powerful on the other.

In conclusion, we have described a typical local characteristic of a large Bangladeshi hospital by focusing on ward boys, gatemen, and cleaners. We have shown how despite being inferior, they are indispensable to the patients as well as to the nurses and doctors. Or, to quote Hadley et al. (2007:1175), "[...] a symbiotic relationship has evolved which allows the hospital system to function; namely hospital support workers fulfil the duties shunned by the nurses while at the same time benefiting by charging for services." Through clever brokering between the different levels of the social hierarchy, they gain considerable 
influence; and by exploiting the power of their intermediary position, they are able to increase their salary by extracting informal payments from patients and relatives.

\section{Acknowledgments}

We are grateful to the hospital staff and patients for their cooperation during the fieldwork. The research was financed by шотво, a division of the Netherlands Organisation for Scientific Research. The article benefitted greatly from the comments of an anonymous reviewer.

\section{References}

Adams, R.N. (1970) "Brokers and Career Mobility Systems in the Structure of Complex Societies." Southwestern Journal of Anthropology 26(4): 315-327.

Andaleeb, S.S. (2000) "Public and Private Hospitals in Bangladesh: Service Quality and Predictors of Hospital Choice." Health Policy \& Planning 15(1): 95-102.

Bailey, F.G. (1963) Politics and Social Change: Orissa in 1959. Berkeley: University of California Press.

Blok, A. (1975) The Mafia of a Sicilian Village, 1860-1960: A Study of Violent Peasant Entrepreneurs. New York: Harper \& Row.

Böhmig, C. (2010) Ghanaian Nurses at a Crossroads: Managing Expectations on a Medical Ward. Leiden: African Studies Centre.

Boissevain, J. (1974) Friends of Friends: Networks, Manipulators and Coalitions. Oxford: Basil Blackwell.

Brown, H. (2012) "Hospital Domestics: Care Work in a Kenyan Hospital." Space and Culture 15(1): 18-30.

Caudill, W. (1958) The Psychiatric Hospital as a Small Community. Cambridge: Harvard University Press.

Coser, R. (1962) Life in the Ward. East Lansing: Michigan State University Press.

Dapaah, J.M. (2012) HIV/AIDs Treatment in Two Ghanaian hospitals. Experiences of Patients, Nurses and Doctors. Leiden: African Studies Centre.

Ferrinho, P., M.C. Omar, M. de Jesus Fernandes, P. Blaise, A.M. Bugalho and W. Van Lerberghe (2004) "Pilfering for Survival: How Health Workers Use Access to Drugs as a Coping Strategy." Human Resources for Health 2: 4.

Finkler, K. (1991) Physicians at Work, Patients in Pain: Biomedical Practice and Patient Responses in Mexico. Boulder, co: Westview Press.

Finkler, K., C. Hunter and R. Iedema (2008) “What is Going on? Ethnography in Hospital Spaces." Journal of Contemporary Ethnography 37(2): 246-250. 
Gibson, D.M. (1999) “The Body in Hospitalization. A Study of Doctors, Nurses and Patients in a Cape Town Teaching Hospital". Unpublished PhD dissertation, University of the Western Cape.

Goffman, E. (1961) Asylums. Harmondsworth: Penguin.

Hadley, M., L.S. Blum, S. Mujaddid, S. Parveen, S. Nuremowlad, M.E. Haquee, M. Ullah (2007) “Why Bangladeshi Nurses Avoid 'Nursing': Social and Structural Factors on Hospital Wards in Bangladesh". Social Science \& Medicine 64 (6): 1166-1177.

Hadley, M. and A. Roques (2007) "Nursing in Bangladesh: Rhetoric and Reality". Social Science \& Medicine 64 (6): 1153-1165.

Henderson, G. and M. Cohen (1983) The Chinese Hospital: A Socialist Work Unit. New Haven: Yale University Press.

Jezewski, M.A. (1990) “Culture Brokering in Migrant Farmworker Health Care”. Western Journal of Nursing Research 12 (4): 497-513.

Jitta, J. and T. Van der Heijden (1993) Economic Survival Strategies of Health Workers in Uganda. Study Report, Child Health and Development Centre, Makerere University, Kampala.

Kirkpatrick, J. (1980) The Sociology of an Indian Hospital. Calcutta: South Asian Books.

Kaufert J.M. and W.W. Koolage (1984) “Role Conflict among 'Culture Brokers': The Experience of Native Canadian Medical Interpreters". Social Science \& Medicine 18 (3): $283^{-286 .}$

Kotalova, J. (1996) "Belonging to Others: Cultural Construction of Womanhood in a Village in Bangladesh". Dhaka: University Press.

Langwick, S.A. (2008) "Articulate(d) Bodies: Traditional Medicine in a Tanzanian Hospital". American Ethnologist 25 (3): 428-439.

Lindquist, J. (2015) "Anthropology of Brokers and Brokerage", in International Encyclopedia of Social and Behavioral Science, 2nd edition. Amsterdam: Elsevier.

Livingston, J. (2012) Improvising Medicine: An African Oncology Ward in an Emerging Cancer Epidemic. Durham: Duke University Press.

Long, D., C. Hunter and S. van der Geest (eds) (2008) "When the Field is a Hospital or a Clinic: Hospital Ethnography". Anthropology \& Medicine 15 (2): 71-78.

Maloney, C. (1986) Behaviour and Poverty in Bangladesh. Dhaka: University Press.

Mannan, M. (2015) BRAC, Global Policy Language, and Women in Bangladesh: Transformation and Manipulation. Albany, NY: State University of New York Press.

Martin, H.M. (2009) Nursing Contradictions: Ideals and Improvisation in Uganda. Diemen: Ам в Publishers.

McPake, B., D. Asiimwe, F. Mwesigye, M. Ofumbi, L. Ortenbladd, P. Streefland and A. Turinde (1999) "Informal Economic Activities of Public Health Workers in Uganda: Implications for Quality and Accessibility of Care." Social Science and Medicine 49: 849-865.

Messing, K. (1998) “Hospital Trash: Cleaners Speak of their Role in Disease Prevention.” Medical Anthropology Quarterly 12(2): 168-187. 
Mulemi, B. (2010) Coping with Cancer and Adversity: Hospital Ethnography in Kenya. Leiden: African Studies Centre.

Praspaliauskiene, R. (2016) "Enveloped Lives: Practicing Health and Care in Lithuania." Medical Anthropology Quarterly 30(4): 582-598.

Rapport, N. (2009) Of Orderlies and Men: Hospital Porters Achieving Wellness at Work. Durham: Carolina Academic Press.

Reeler, A. (1996) Money and Friendship: Modes of Empowerment in Thai Health Culture. Amsterdam: Het Spinhuis.

Rhodes, L.A. (1990) Emptying Beds: The Work of an Emergency Psychiatric Unit. Berkeley: University of California Press.

Rosendal Østergaard, L. (2015) “Trust Matters: A Narrative Literature Review of the Role of Trust in Health Care Systems in Sub-Saharan Africa." Global Public Health: An International Journal for Research, Policy and Practice 10(9): 1046-1059.

Roy, A. (2009) "Why India Cannot Plan its Cities: Informality, Insurgence and the Idiom of Urbanization." Planning Theory 8(1): 76-87.

Sachs, L. and G. Tomson (1994) "Brokers, Medicines and Rationality: Mirroring Health Centers in Sri Lanka and Sweden," in N.L. Etkin and M.L. Tan (eds.) Medicines, Meanings and Contexts. Quezon City: HAIN, Pp. 265-285.

Schwab, B., R.E. Drake and E.M. Burghard (1988) "Health Care of the Chronically Mentally Ill: The Culture Broker Model." Community Mental Health Journal 24(3): 174184.

Sciortino, R. (1992) Caretakers of Cure: An Anthropological Study of Health Centre Nurses in Rural Central Java. Bulaksumur: Gadjah Mada University Press.

Stein W.W. (1995) A Peruvian Psychiatric Hospital. Lanham, MD: University Press of America.

Street, A. (2012) "Affective Infrastructure: Hospital Landscapes of Hope and Failure." Space and Culture 15(1): 44-56.

Street, A. (2014) Biomedicine in an Unstable Place: Infrastructure and Personhood in a Papua New Guinean Hospital. Durham / London: Duke University Press.

Street, A. and S. Coleman (eds.) (2012) "Hospital Heterotopias: Ethnographies of Biomedical and Non-Biomedical Spaces." Space and Culture 15(1).

Tantchou, J.C. (2014) "Blurring Boundaries: Structural Constraints, Space, Tools, and Agency in an Operating Theater." Science, Technology \& Human Values 39(3): 336373 .

Van der Geest, S. (1982) “The Efficiency of Inefficiency: Medicine Distribution in South Cameroon." Social Science and Medicine 16(24): 2145-2153.

Van der Geest, S. (1988) "The Articulation of Formal and Informal Medicine Distribution in South Cameroon," in S. van der Geest and S.R. Whyte (eds.) The Context of Medicines in Developing Countries: Studies in Pharmaceutical Anthropology. Dordrecht: Reidel, Pp. 131-148. 
Van der Geest, S. and K. Finkler (2004) "Hospital Ethnography: Introduction." Social Science and Medicine 59(10): 1995-2001.

Whitehead, T.L. (1984) “The Buccra-Massa and the Little Man's Broker in a Jamaican Sugartown: Implications for Community Health Education." Social Science and Medicine $19(5): 561-172$.

Zaman, S. (2004) "Poverty and Violence, Frustration and Inventiveness: Hospital Ward Life in Bangladesh." Social Science and Medicine 59(10): 2025-2036.

Zaman, S. (2005) Broken Limbs, Broken Lives: Ethnography of a Hospital Ward in Bangladesh. Amsterdam: Het Spinhuis.

Zaman, S. (2008) "Native among the Natives: Physician Anthropologist Doing Hospital Ethnography at Home." Journal of Contemporary Ethnography 37(2): 137-154.

Zaman, S. (2009) "Ladies without Lamps: Nurses in Bangladesh." Qualitative Health Research 19(3): 366-374. 